\title{
Nucleofection induces non-specific changes in the metabolic activity of transfected cells
}

\author{
Fernanda Mello de Queiroz • Araceli Sánchez • \\ Jasmin Roya Agarwal · Walter Stühmer • \\ Luis A. Pardo
}

Received: 15 December 2010/ Accepted: 26 May 2011/Published online: 5 June 2011

(C) The Author(s) 2011. This article is published with open access at Springerlink.com

\begin{abstract}
Transfection has become an everyday technique widely used for functional studies in living cells. The choice of the particular transfection method is usually determined by its efficiency and toxicity, and possible functional consequences specific to the method used are normally overlooked. We describe here that nucleofection, a method increasingly used because of its convenience and high efficiency, increases the metabolic rate of some cancer cells, which can be misleading when used as a measure of proliferation. Moreover, nucleofection can alter the subcellular expression pattern of the transfected protein. These undesired effects are independent of the transfected nucleic acid, but depend on the particular cell line used. Therefore, the interpretation of functional data using this technology requires further controls and caution.
\end{abstract}

Keywords Nucleofection - Lipofection - Proliferation . Metabolic activity

F. Mello de Queiroz · A. Sánchez · J. R. Agarwal .

W. Stühmer · L. A. Pardo $(\bowtie)$

Max-Planck-Institut für experimentelle Medizin, Abteilung

Molekulare Biologie Neuronaler Signale, Hermann-Rein-Strasse

3, 37075 Göttingen, Germany

e-mail: pardo@em.mpg.de

F. Mello de Queiroz

e-mail: fqueiroz_21@hotmail.com

A. Sánchez

e-mail: sanchez@em-mpg.de

J. R. Agarwal

e-mail: Jasmin.Agarwal@jhmi.edu

W. Stühmer

e-mail: ws@em.mpg.de

\section{Introduction}

Transfection is the process of introducing foreign nucleic acids into a cell. There are many different methods to transfect cells, such as cationic polymers [1], precipitation with calcium phosphate [2], lipid-based transfection [3, 4], microinjection/gene gun [5] and electroporation [6]. Among them, electroporation-based technologies have gained popularity because of their efficiency and relatively low toxicity. Nucleofection is a form of electroporation that combines electrical pulses with specific solutions (adapted to the target cell line) to induce direct probe transfer into the cell nucleus [7]. Nucleofection results in higher transfection efficiency and less inter-experimental variation than lipid-based transfection and is widely used for primary cells and cell lines. In fact, it is frequently the first choice for the transfection of primary cells, and often the only non-viral method with reasonable yield. Moreover, electroporation-based transfection has not been described to cause off-target effects by itself.

Transfection of a foreign DNA or RNA into a cell is an important tool for cellular biology and a frequent experimental outlook after the transfection is the subsequent measurement of proliferation, often through redox-based technologies, like MTT [8], AlamarBlue [9] or related methods. These methods are based on the reduction of a reagent in living mitochondria to render a colored or fluorescent product. A linear correlation between redoxbased and other methods to determine cell proliferation (cell counting, bromodeoxy-uridine or $\left[{ }^{3} \mathrm{H}\right]$-thymidine incorporation, flow cytometry) has been repeatedly reported [10-12], and the simplicity of redox-based approaches makes them the preferred method in many laboratories.

With the aim of extending our panel of studied lines, we decided to migrate our transfection methodology to 
nucleofection because of difficulties in transfecting some cell lines. In the process, we compared the results of proliferation experiments from cell lines transfected by our already standardized lipofection [13] or nucleofection. Here we report alterations of the MTT signal that is directly dependent on nucleofection of several, but not all, cell lines tested. The transfection method also altered the subcellular distribution of the recombinant protein in some cell lines.

\section{Materials and methods}

\section{Cell lines}

All cell lines were obtained from DSMZ (Braunschweig, Germany). The lines used in this study were the prostatederived adherent cell lines LNCaP (ACC 256), PC3 (ACC 465) and DU145 (ACC 261); the rhabdomyosarcomaderived cell line TE671 (ACC 263), the mouse fibroblast NIH-3T3 (ACC 59) and the leukemia-derived suspension cell lines K562 (ACC 10) and PLB895 (ACC 139). Each cell line was propagated and maintained according to the instructions of the provider.

\section{Transfection}

Cells were transfected using either Lipofectamine 2000 (Invitrogen $\mathrm{GmbH}$, Karlsruhe, Germany), Dreamfect (OZ Biosciences, Marseille, France), or Amaxa Nucleofection (Lonza, Cologne, Germany). Cells were plated 1 day before chemically based transfections, which were performed in OptiMEM medium. The cells were incubated with the siRNA or the vehicle for $6 \mathrm{~h}$, or overnight for DNA. After the $6 \mathrm{~h}$ incubation period, cells were seeded in 96-well plates and allowed to recover for 24-96 h before proliferation assays were performed. Cells treated only with OptiMEM and the corresponding vehicle were included as controls. Amaxa Nucleofection was performed according to the instructions of the provider using the following solution/program for each cell line: LNCaP, R/T-009; PC3, V/T-013; DU145, L/A-023; TE671, L/R-005; K562, V/T-003; PLB895, V/C-023 and NIH-3T3, R/A-024. Adherent cells were plated after nucleofection and allowed to recover for 24-96 h prior to metabolic activity determinations. Suspension cells were seeded for proliferation assays after $24 \mathrm{~h}$ recovery.

\section{Real time PCR}

Total RNA was isolated from all cell lines using the RNeasy mini isolation kit for animal cells (Qiagen, Hilden, Germany). cDNA synthesis and real time PCR were performed as previously described $[13,14]$. Data analysis was performed using the $-2^{\Delta \Delta \mathrm{CT}}$ method.
Proliferation assay

Cell proliferation of the adherent cell lines was determined by measuring the metabolic activity via reduction of the tetrazolium salt MTT (3-[4,5-dimethylthiazol-2]-2,5diphenyltetrazolium bromide; Sigma, Munich, Germany) for adherent cell lines or via the reduction of resazurin to resorufin (AlamarBlue; Invitrogen) in the case of nonadherent cell lines. Cells were plated at a density of $10000-20000$ cells $/ \mathrm{ml}$. MTT $(5 \mathrm{mg} / \mathrm{ml})$ was added to the cultures 24-96 h after transfection. Two hours later, the reaction was stopped and the product solubilized using $10 \%$ SDS in $0.01 \mathrm{M} \mathrm{HCl}$. After overnight incubation, the color was read at $562 \mathrm{~nm}$. AlamarBlue was added to the culture of non-adherent cell lines at 24 and $48 \mathrm{~h}$ after the transfection. Following $2 \mathrm{~h}$ incubation, the color was read at $570 \mathrm{~nm}$.

Growth rate and viability

Vybrant ${ }^{\mathrm{TM}} \mathrm{DiO}$ (Invitrogen) was added to the cultures after transfection. Following incubation of $20 \mathrm{~min}$, cells were seeded into 6-well plates and harvested at different time points (2, 4 and 6 days). The data was measured using the BD FACSAria flow cytometer (Becton Dickinson, Heidelberg, Germany). The fluorophore was excited at $488 \mathrm{~nm}$ and fluorescence collected using a LP502 dichroic mirror and BP510/20 filter. The analysis of doubling-time was performed using the mean fluorescence given by FACSDiva software (Becton Dickinson) as previously described [15]. To measure cellular viability, cells were harvested 2 , 4 and 6 days after transfection. Samples were washed with PBS and propidium iodide $(0.1 \mu \mathrm{g} / \mathrm{ml})$ was added to the mix. Cells were incubated for 2-5 min and analyzed using the BD FACSAria flow cytometer. Propidium iodide positive cells were considered dead cells.

Cell cycle

Following transfection, cells were seeded into 6-well plates and harvested at different time points (24,48 and $72 \mathrm{~h}$ ). Cells were washed with PBS and the pellet was resuspended in a solution containing: propidium iodide $(50 \mu \mathrm{g} / \mathrm{ml})$, saponin $(0.3 \%)$ and RNase $(100 \mathrm{U} / \mathrm{ml})$ in PBS. After 15 min incubation at $4^{\circ} \mathrm{C}$, samples were analyzed with BD FACSAria flow cytometer. The propidium iodide was excited at $488 \mathrm{~nm}$ and fluorescence collected using a LP595 dichroic mirror and BP610/20 filter. The data were analyzed using FlowJo software (Tree Star Inc., Ashland, OR, USA).

Fluorescence microscopy

Cells were transfected using either Amaxa nucleofection or PolyFect. In the first case, the cells were transfected in 
suspension and then plated on glass coverslips; in the case of Polyfect, cells were transfected directly on the glass coverslips. $48 \mathrm{~h}$ after transfection, the cells were fixed in $10 \%$ buffered formalin, nuclei were stained with ToPro3 and coverslips mounted using ProLong Gold antifade reagent. The preparations were imaged using a conventional epifluorescence microscope (Axioskop II) or a confocal microscope (LSM 510Meta, Zeiss, Jena, Germany).

\section{Statistical analysis}

Unpaired t test and one-way ANOVA were performed for comparison of the values. The software GraphPad Prism version 4 was applied for the analysis.

\section{Results}

\section{Transfection efficiency}

We first compared the efficiency of knockdown using chemical or electrical transfection. To do this, we compared the knockdown efficiency of a GAPDH siRNA by real time RT-PCR that has been repeatedly used in previous reports $[13,16]$. Since the transfected sequence was the same in all cases, we assumed that the knockdown level would be proportional to the transfection efficiency for a given cell line. We used a commercial negative control as reference, and the transferrin receptor as PCR reference gene.

Figure 1 shows the changes in GAPDH RNA content in four different cell lines using lipo- or nucleofection. We observed a larger effect using nucleofection for TE671 $(P<0.0005)$ and using lipofection for DU145 and LNCaP $(P<0.05)$, which may reflect a better transfection efficiency. The minimal reduction observed was in the order of $50 \%$. The knockdown of mRNA for GAPDH was achieved in all cases regarding the transfection method used.

\section{Metabolic activity}

We then performed AlamarBlue (non-adherent cell lines) or MTT (adherent cell lines) tests to assess the proliferation of cells upon knockdown of GAPDH. Since the enzyme is required for glycolysis, we expected a reduction in metabolic activity in both assays that should be related to decreased proliferation. However, we observed a nonspecific increase in metabolic activity in some cell lines even due to incubation with the vehicle alone. The effect was due solely to the transfection process, since it was in fact observed in the absence of any nucleic acid (Fig. 2). Moreover, controls using only the transfection solution but not performing the transfection process did not alter the metabolic rate of the cells studied (data not shown). The increase in MTT signal was especially noticeable in DU145 cells (Fig. 2a), which showed twice as much signal after mock nucleofection than the control. LNCaP cells (Fig. 2b), in contrast, showed no alteration of the MTT signal attributable to the transfection process. TE671 and PC3 cells showed 60 and 30\% increase respectively (Fig. 2c, d). Also, lipofection did not alter the MTT signal in any of the prostate-derived cells lines tested. While lipofection of GAPDH siRNA resulted in a dramatically decreased MTT signal in all cell lines, the apparent effect of nucleofection was strongly attenuated and only visible if compared to control transfections. Although there was some reduction of the MTT signal in most cell lines after transfection with GAPDH siRNA as compared to scrambled siRNA, the effect even completely vanished in

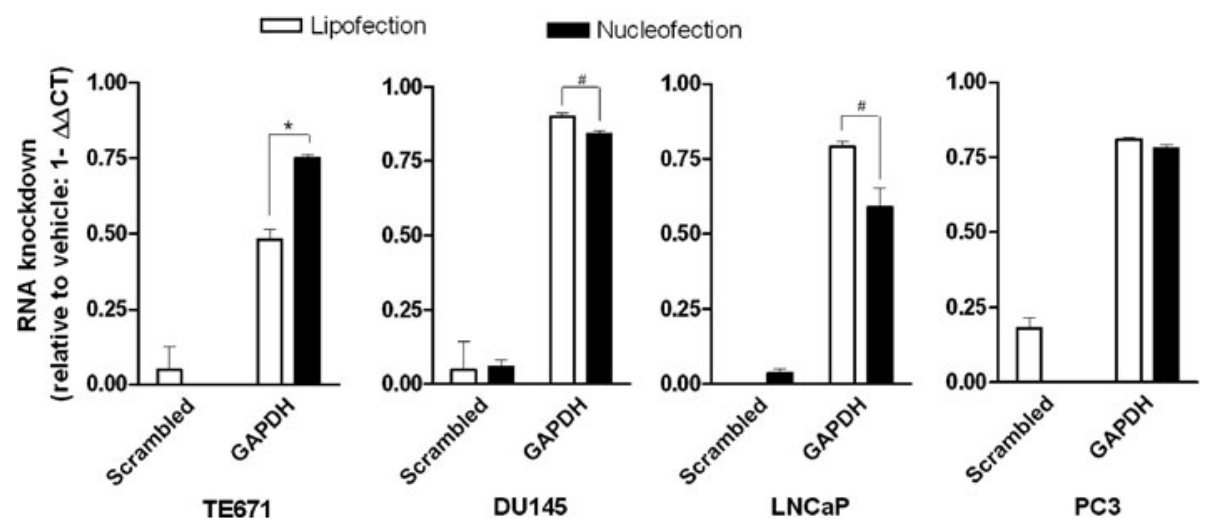

Fig. 1 mRNA levels of GAPDH of tumor cells treated with lipofection or nucleofection. Tumor cells were transfected with vehicle only, scrambled or siRNA against GAPDH using lipofection (white bars) or nucleofection (black bars). After $24 \mathrm{~h}$, the levels of

GAPDH mRNA were measured by real-time PCR. Nucleofection and lipofection are similarly effective in knocking down GAPDH mRNA. Data was normalized against mock-transfect cells and it represents mean \pm standard error $(n=3)$. ${ }^{*} P<0.0005$; ${ }^{\#} P<0.05$ 


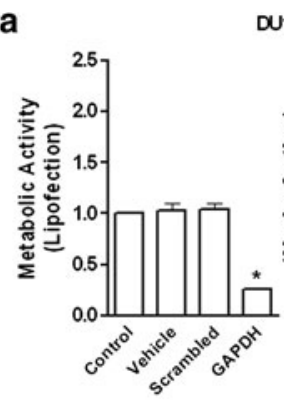

DU145

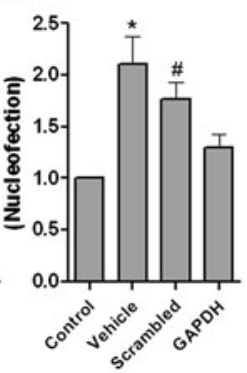

b

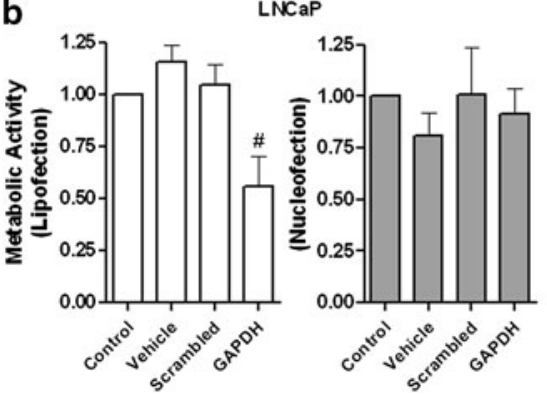

d

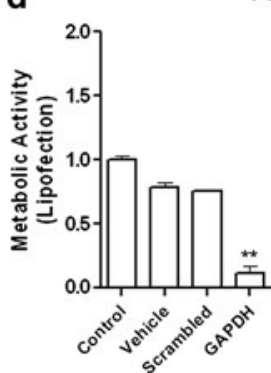

Fig. 2 Metabolic activity of tumor cells. The metabolic activity of tumor cells was measured either by MTT in the case of DU145, LNCaP, PC3 and TE671 or AlamarBlue in the case of K562 and PLB895. The effect on the metabolic activity after non-treatment

LNCaP. Importantly, LNCaP was the cell line that showed least increase in MTT signaling by mock nucleofection.

A relevant methodological difference between lipo- and nucleofection is that the latter is done in suspension and therefore cell trypsinization is required before nucleofection. To account for this difference, we performed equivalent experiments to the ones shown in Fig. 2 in cell lines normally grown in suspension (Fig. 3). Vehicle nucleofection increased the metabolic rate of K562 cells (Fig. 3a) measured by AlamarBlue; this effect was statistically significant when compared to exposure to the transfection solution alone (not shown). The treatment even induced doubling of the signal for PLB985 cells (an effect also observed after lipofection; Fig. 3b). Therefore, we conclude that the changes in MTT signal are not due to trypsinization. Intriguingly, lipofection also altered the AlamarBlue signal in the non-adherent cell lines. In PLB985 cells, lipofection clearly increased the signal, while it decreased it in K562 cells.

\section{Changes in MTT signal do not reflect changes} in proliferation

Since the methods applied to estimate proliferation rely on the reducing ability of cells, we performed experiments to test if the correlation between this parameter and the proliferation is disrupted by nucleofection. We directly measured growth rate, cell cycle distribution and cell viability
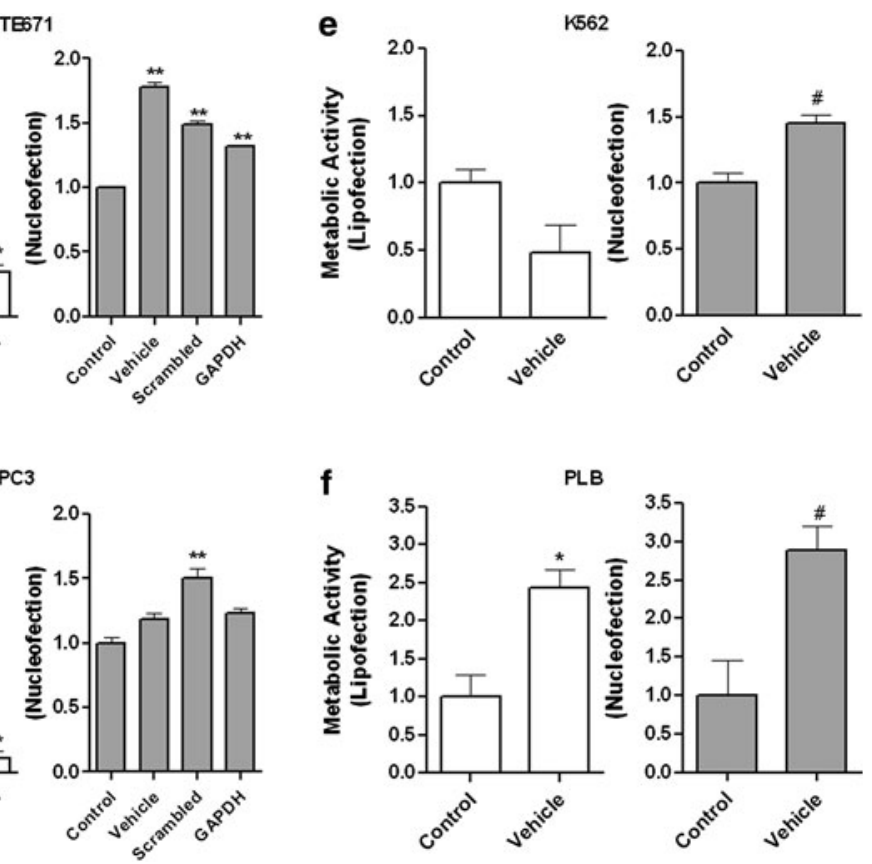

(control) or treatment with lipofection (white bars) or nucleofection (grey bars) is shown. The assay was performed $96 \mathrm{~h}$ after the transfection procedure. Data represents mean \pm standard error $(n=3)$. ${ }^{*} * P<0.001,{ }^{\#} P<0.05,{ }^{*} P<0.01$

by flow cytometry. In order to evaluate growth of the studied cells, we used the Vybrant DiO, which is a membrane-bound dye. It remains bound to the cell and is not transferred from cell to cell nor does it affect the cellular growth rate. Once a cell divides, each daughter cell will receive one-half of the total dye present in the parent cell. The growth rate can therefore be determined by the reduction in the total fluorescence per cell. When comparing the growth rate of cells after nucleofection with no or with control siRNA, no differences were observed (Fig. 3a) that can be attributed to the transfection process.

We also determined the cell viability 4 days after transfection by propidium iodide exclusion. As expected, nucleofection using the appropriate solution does not impair cell survival. Cells did not lose viability with the treatment, with the exception of a slight decrease in the case of DU145 cells (Fig. 3b), confirming the low toxicity of nucleofection.

Finally, we also determined cell cycle distribution also after nucleofection (Fig. 3c), since real changes in proliferation rates are often correlated with enrichment in the fraction of cells in some phase of the cycle, typically G1. We did not observe any effect in any of the cell lines tested. Although unaltered cell cycle distribution does not unequivocally indicate unaltered proliferation, it excludes cell arrests in any phase of the cycle during the transfection process.

Altogether, our results strongly suggest that the observed alterations in MTT and/or AlamarBlue signals do 

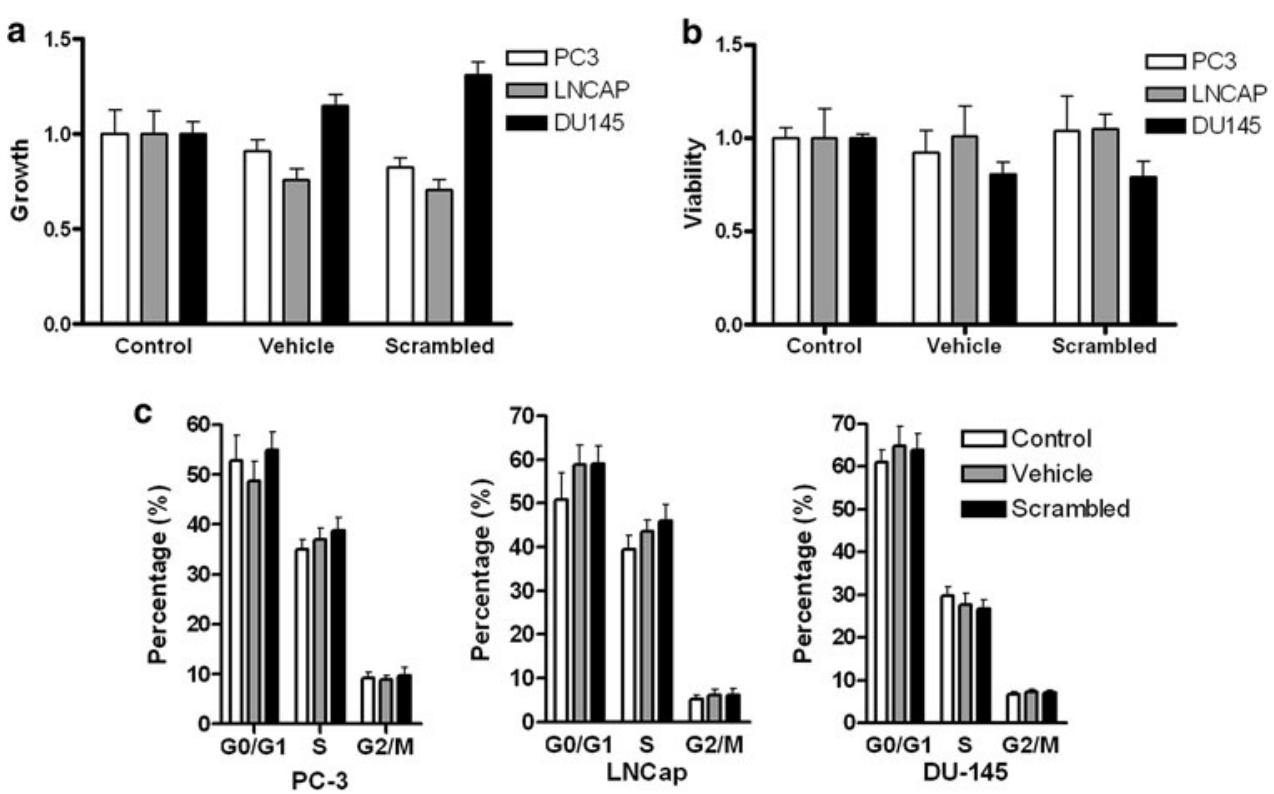

Fig. 3 Growth rate and viability and cell cycle measurement of tumor cells after nucleofection treatment. a 6 days after transfection, the growth rate of PC3 (white bars), LNCaP (grey bars) and DU145 (black bars) was measured by flow cytometry using Vibrant DiO. b Viability was measured by propidium iodide-exclusion at 6 days after transfection. c Cell cycle was determined by flow cytometry at

not reflect actual changes in cell proliferation, but rather are artifactually induced by the transfection method itself.

Subcellular distribution

Nucleofection also changed the subcellular distribution of a fluorescent fusion protein between the ion channel $\mathrm{K}_{\mathrm{V}} 10.1$ and the modified yellow fluorescent protein monomeric Venus $\left(\mathrm{K}_{\mathrm{V}} 10.1-\right.$ Venus expressed in pcDNA3) in comparison to chemical transfection in NIH-3T3 cells.

Chemical transfection resulted in a diffuse punctate pattern throughout the whole cell (Fig. 4). Such a distribution has repeatedly been reported in native systems and heterologous systems using anti- $\mathrm{K}_{\mathrm{V}} 10.1$ antibodies [14, 17-19]. It has also been observed in HEK293 and CHO cells using the same construct $[14,20]$. Nucleofection of NIH-3T3 cells was much more efficient than lipofection, as expected from the data provided by the manufacturer (http://www.lonzabio.com/no_cache/meta/cell-database/ cell-details/cell/123/), but induced a dramatically different intracellular distribution pattern of the protein, with most of the signal concentrated inside the nucleus. This apparently aberrant expression pattern did not correlate with signal intensity. We did not observe any alteration of the distribution pattern of mVenus alone (also in pcDNA3) regardless of the transfection method used. It is important to keep in mind that the effect was specific for this particular cell line and no noticeable differences were
4 days after transfection. Nucleofection had no effect on the growth rate, viability or cell cycle phases. Prostate-derived tumor cells were transfected with vehicle only (grey bars) or scrambled siRNA (black bars) using nucleofection. Non-transfected cells (white bars) were used as control. Data represents mean \pm standard error $(n=3)$

observed regarding protein distribution in HEK293 cells (data not shown).

\section{Discussion}

It is a general assumption that transfection can induce changes in the behavior of cells. Recently, Mo et al showed that the nucleofection process is able to disrupt the tight junction fence and thereby alter the membrane polarity of renal epithelial cells [21]. An important question that remains open is if other cellular properties can be altered by nucleofection. Electroporation-based technologies, particularly nucleofection, are popular transfection methods. The reason for this growing popularity is that nucleofection yields relatively high transfection efficiency also in difficult cell models, particularly primary cells. Our data is the first indicative that nucleofection can induce dramatic changes in the cellular behavior in downstream cell biological analysis.

The effects of electric fields (low-, intermediate- and high-intensity) on cells are not entirely understood. Due to biomedical engineering, a large body of literature on the application of electrical pulses has been generated and is still actively growing. Electroporation uses high electric fields to permeabilize biomembranes in a reversible way by creating structural distortions. The technique was first used by Neumann et al. [22] to allow the uptake of DNA into 

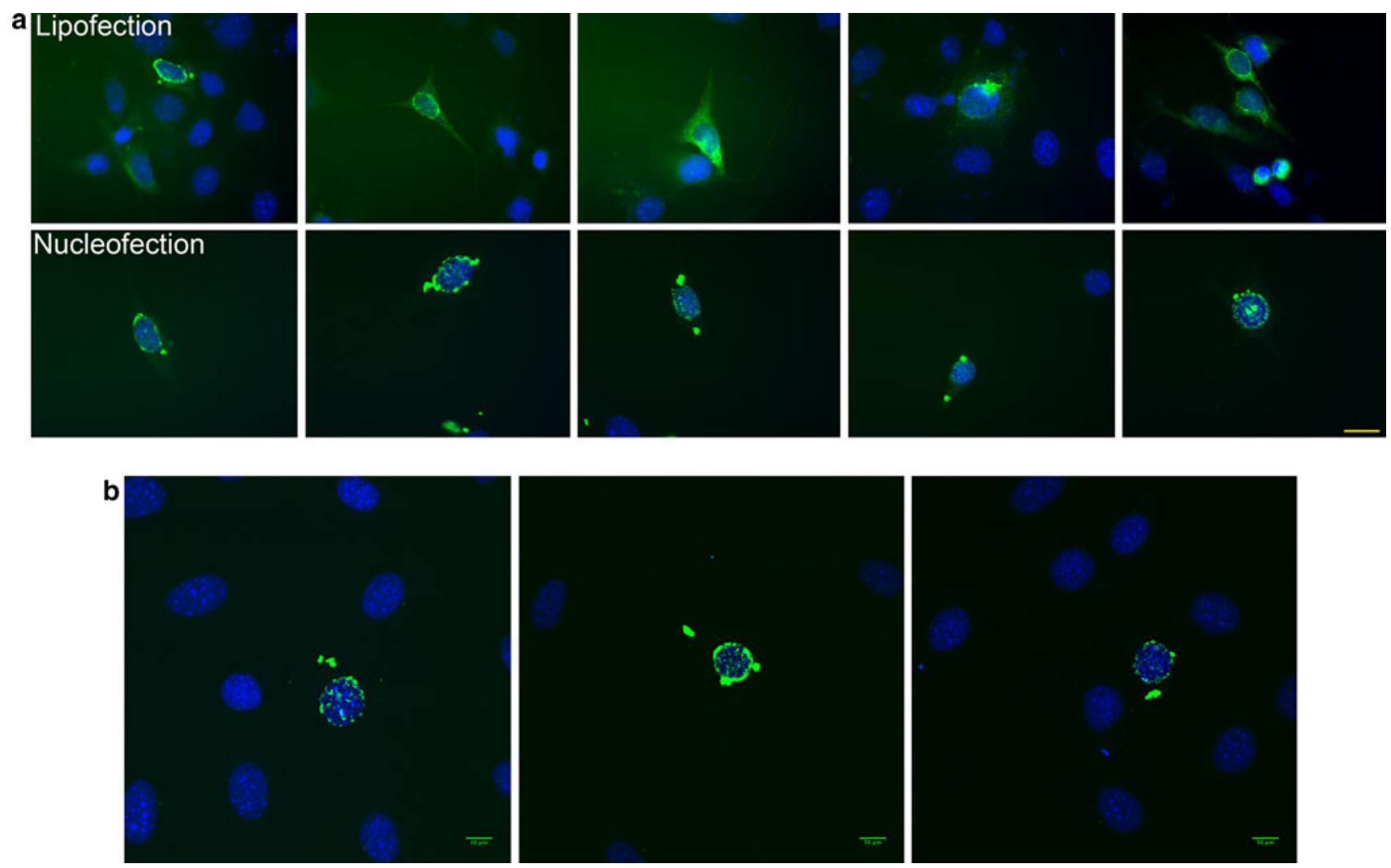

Fig. 4 Intracellular distribution of Venus-labeled $\mathrm{K}_{\mathrm{V}} 10.1$ channels varies with the method of transfection in NIH-3T3 cells. a Nucleofection induced intense signals in and around the nucleus (stained with ToPro3) in virtually all cells (lower panels) while lipofection (upper panels) gave rise to a comparable phenotype only in rare cases, and intense intranuclear signals were never observed. Scale bar: $10 \mu \mathrm{m}$. b Examples of $0.5 \mu \mathrm{m}$-thick confocal slices of cells transfected with a $\mathrm{K}_{\mathrm{V}} 10.1-\mathrm{Venus}$ construct using nucleofection. The protein is located in intranuclear aggregates

mechanisms responsible for the formation of mitotic spindles [29]. Our observations add the nucleofection method to the conditions that render metabolic assays unreliable to estimate proliferation [30], but importantly in a cell line-specific fashion. Moreover, we detected dramatic differences on the distribution of the $\mathrm{K}_{\mathrm{V}} 10.1-\mathrm{Venus}$ in NIH-3T3 cells, an effect that was neither observed for the same protein in other cell lines, nor for Venus alone in this cell line. This could reflect a permeabilization of the nuclear envelope during an extended period, which would affect the distribution of certain proteins. Imaging was performed $48 \mathrm{~h}$ after transfection; it is not clear if the nuclear electropores had been closed after that time, because we do not know if the protein accumulated in the nucleus was trapped there during the first hours of production and could not escape when the cell completely recovered.

Our data indicate that nucleofection can induce dramatic changes in the cellular behavior in cell biological downstream analysis. The changes are not constant for all cell lines, nor can they be easily predicted. It continues to be a very efficient, and in many cases, the method of choice, but 
caution is advisable when interpreting data obtained after cell nucleofection. We propose that certain standards have to be set for the publication of transfection experiments. When applying any transfection method to a new cell line proper control experiments have to be performed at the beginning of any study. This should include the evaluation if the chosen method for metabolic rate changes is truly linear to cell proliferation and immunocytochemical stainings to ensure that the transfected protein is properly distributed in the cell. All following experiments have to include controls like vehicle transfections to ensure correct comparisons. Such standards will greatly increase the reliability of reported data.

Acknowledgments We wish to thank Víctor Díaz-Salamanca, Ursula Kutzke and Annett Sporning for their excellent and diligent technical work.

Disclosure The authors declare that they have no conflict of interest.

Open Access This article is distributed under the terms of the Creative Commons Attribution Noncommercial License which permits any noncommercial use, distribution, and reproduction in any medium, provided the original author(s) and source are credited.

\section{References}

1. McCutchan JH, Pagano JS (1968) Enchancement of the infectivity of simian virus 40 deoxyribonucleic acid with diethylaminoethyl-dextran. J Natl Cancer Inst 41:351-357

2. Graham FL, van der Eb AJ (1973) A new technique for the assay of infectivity of human adenovirus 5 DNA. Virology 52:456-467

3. Felgner PL, Gadek TR, Holm M, Roman R, Chan HW, Wenz M, Northrop JP, Ringold GM, Danielsen M (1987) Lipofection: a highly efficient, lipid-mediated DNA-transfection procedure. Proc Natl Acad Sci USA 84:7413-7417

4. Cudd A, Labbe H, Gervais M, Nicolau C (1984) Liposomes injected intravenously into mice associate with liver mitochondria. Biochim Biophys Acta 774:169-180

5. Muller C, Grassmann A, Grassmann M (1981) Techniques for the microinjection of single cells. Biochem Soc Trans 9:585-587

6. Chu G, Hayakawa H, Berg P (1987) Electroporation for the efficient transfection of mammalian cells with DNA. Nucleic Acids Res 15:1311-1326

7. Gresch O, Engel FB, Nesic D, Tran TT, England HM, Hickman ES, Korner I, Gan L, Chen S, Castro-Obregon S, Hammermann R, Wolf J, Muller-Hartmann H, Nix M, Siebenkotten G, Kraus G, Lun K (2004) New non-viral method for gene transfer into primary cells. Methods 33:151-163

8. Mosmann T (1983) Rapid colorimetric assay for cellular growth and survival: application to proliferation and cytotoxicity assays. J Immunol Methods 65:55-63

9. Hamid R, Rotshteyn Y, Rabadi L, Parikh R, Bullock P (2004) Comparison of alamar blue and MTT assays for high through-put screening. Toxicol In Vitro 18:703-710

10. Bounous DI, Campagnoli RP, Brown J (1992) Comparison of MTT colorimetric assay and tritiated thymidine uptake for lymphocyte proliferation assays using chicken splenocytes. Avian Dis 36:1022-1027

11. Wang YY, Zheng XX (2002) A flow cytometry-based assay for quantitative analysis of cellular proliferation and cytotoxicity in vitro. J Immunol Methods 268:179-188

12. Weichert H, Blechschmidt I, Schroder S, Ambrosius H (1991) The MTT-assay as a rapid test for cell proliferation and cell killing: application to human peripheral blood lymphocytes (PBL). Allerg Immunol (Leipz) 37:139-144

13. Weber C, Mello de Queiroz F, Downie BR, Suckow A, Stuhmer W, Pardo LA (2006) Silencing the activity and proliferative properties of the human EagI Potassium Channel by RNA Interference. J Biol Chem 281:13030-13037

14. Hemmerlein B, Weseloh RM, Mello de Queiroz F, Knotgen H, Sanchez A, Rubio ME, Martin S, Schliephacke T, Jenke M, Heinz Joachim R, Stuhmer W, Pardo LA (2006) Overexpression of Eag1 potassium channels in clinical tumours. Mol Cancer 5:41

15. Ashley DM, Bol SJ, Waugh C, Kannourakis G (1993) A novel approach to the measurement of different in vitro leukaemic cell growth parameters: the use of PKH GL fluorescent probes. Leuk Res 17:873-882

16. Mello de Queiroz F, Suarez-Kurtz G, Stuhmer W, Pardo LA (2006) Ether a go-go potassium channel expression in soft tissue sarcoma patients. Mol Cancer 5:42

17. Diaz L, Ceja-Ochoa I, Restrepo-Angulo I, Larrea F, Avila-Chavez E, Garcia-Becerra R, Borja-Cacho E, Barrera D, Ahumada E, Gariglio P, Alvarez-Rios E, Ocadiz-Delgado R, Garcia-Villa E, Hernandez-Gallegos E, Camacho-Arroyo I, Morales A, OrdazRosado D, Garcia-Latorre E, Escamilla J, Sanchez-Pena LC, Saqui-Salces M, Gamboa-Dominguez A, Vera E, Uribe-Ramirez M, Murbartian J, Ortiz CS, Rivera-Guevara C, De Vizcaya-Ruiz A, Camacho J (2009) Estrogens and human papilloma virus oncogenes regulate human ether-a-go-go-1 potassium channel expression. Cancer Res 69:3300-3307

18. Gómez-Varela D, Kohl T, Schmidt M, Rubio ME, Kawabe H, Nehring RB, Schafer S, Stühmer W, Pardo LA (2010) Characterization of Eag1 channel lateral mobility in rat hippocampal cultures by single-particle-tracking with quantum dots. PLoS One $5: \mathrm{e} 8858$

19. Toral C, Mendoza-Garrido ME, Azorin E, Hernandez-Gallegos E, Gomora JC, Delgadillo DM, Solano-Agama C, Camacho J (2007) Effect of extracellular matrix on adhesion, viability, actin cytoskeleton and $\mathrm{K}+$ currents of cells expressing human ether a go-go channels. Life Sci 81:255-265

20. Gómez-Varela D, Zwick-Wallasch E, Knotgen H, Sanchez A, Hettmann T, Ossipov D, Weseloh R, Contreras-Jurado C, Rothe M, Stühmer W, Pardo LA (2007) Monoclonal antibody blockade of the human Eag1 potassium channel function exerts antitumor activity. Cancer Res 67:7343-7349

21. Mo D, Potter BA, Bertrand CA, Hildebrand JD, Bruns JR, Weisz OA (2010) Nucleofection disrupts tight junction fence function to alter membrane polarity of renal epithelial cells. Am J Physiol 299:F1178-F1184

22. Neumann E, Schaefer-Ridder M, Wang Y, Hofschneider PH (1982) Gene transfer into mouse lyoma cells by electroporation in high electric fields. EMBO J 1:841-845

23. $\mathrm{Hu}$ Q, Joshi RP (2009) Transmembrane voltage analyses in spheroidal cells in response to an intense ultrashort electrical pulse. Phys Rev E Stat Nonlin Soft Matter Phys 79:011901

24. Vernier PT, Sun Y, Marcu L, Salemi S, Craft CM, Gundersen MA (2003) Calcium bursts induced by nanosecond electric pulses. Biochem Biophys Res Commun 310:286-295

25. Stacey M, Stickley J, Fox P, Statler V, Schoenbach K, Beebe SJ, Buescher S (2003) Differential effects in cells exposed to ultrashort, high intensity electric fields: cell survival, DNA damage, and cell cycle analysis. Mutat Res 542:65-75 
26. Nuccitelli R, Pliquett U, Chen X, Ford W, James Swanson R, Beebe SJ, Kolb JF, Schoenbach KH (2006) Nanosecond pulsed electric fields cause melanomas to self-destruct. Biochem Biophys Res Commun 343:351-360

27. Schoenbach KH, Joshi R, Kolb J, Buescher S, Beebe S (2004) Subcellular effects of nanosecond electrical pulses. Conf Proc IEEE Eng Med Biol Soc 7:5447-5450

28. Cucullo L, Dini G, Hallene KL, Fazio V, Ilkanich EV, Igboechi C, Kight KM, Agarwal MK, Garrity-Moses M, Janigro D (2005)
Very low intensity alternating current decreases cell proliferation. Glia 51:65-72

29. Kirson ED, Gurvich Z, Schneiderman R, Dekel E, Itzhaki A, Wasserman Y, Schatzberger R, Palti Y (2004) Disruption of cancer cell replication by alternating electric fields. Cancer Res 64:3288-3295

30. Funk D, Schrenk HH, Frei E (2007) Serum albumin leads to false-positive results in the XTT and the MTT assay. Biotechniques $43: 178,180,182$ passim 